\title{
A Pilot Study of the Swedish Sexual Offender Treatment Program
}

\author{
Stina Lindegren'
}

@SAGE

\begin{abstract}
Purpose: The aim was to test whether dynamic criminogenic risk factors change after participation in a new cognitivebehavioral treatment program adhering to the Risk-Need-Responsivity (RNR) model, within a group of adult men convicted of a sexual offense in Sweden. Methods: Three psychometric tests from approximately 26 participants were completed. Therapists rated 46 participants using the Therapist Rating Scale-2 (TRS-2). Results: Participants reported a significant decrease in hypersexuality, small to medium effect size, a non-significant, increased, internal locus of control, but no change regarding attachment styles, posttreatment. Therapists rated significant decrease in all treatment needs posttreatment, medium to large effect size. Conclusions: The significant reduction of several criminogenic risk factors posttreatment indicates the treatment program may reduce problems related to increased risk of recidivism, especially hypersexuality. Moreover, treatment did not appear to have negative effects, motivating further implementation. However, to evaluate the effectiveness, more research is necessary.
\end{abstract}

\section{Keywords}

sexual offender treatment, criminogenic needs, hypersexuality, attachment, locus of control

In order to prevent relapse in sexual crimes, measures such as treatment programs for individuals who have committed sexual offenses are important. The matter of the evidence however is highly debated among scholars. Some have suggested there is evidence for sexual offender treatment programs (Kim, Benekos, \& Merlo, 2016; Marshall \& Marshall, 2007), while others have expressed doubts and argued there is still a of lack of high-quality methodological study designs (Dennis et al., 2012; Grønnerød, Grønnerød, \& Grøndahl, 2015; Långström et al., 2013; Seto et al., 2008). A large number of meta-analyses and systematic reviews demonstrate significant decrease in recidivism, especially for treatment programs based on cognitive behavioral therapy (CBT) and adherence to the Risk-Need-Responsivity (RNR) model (Bonta \& Andrews, 2017; Gannon et al., 2019; Hanson et al., 2009; Kim et al., 2016; Mpofu et al., 2018; Schmucker \& Lösel, 2008, 2015, 2017; Soldino \& Carbonell-Vayá, 2017). In short, the RNR model (Bonta \& Andrews, 2017) proposes rehabilitation intensity should increase for individuals with higher risk of recidivism (the Risk principle). Moreover, rehabilitation ought to target criminogenic needs, that is, factors related to recidivism risk (the Need principle). Finally, according to the Responsivity principle, rehabilitative measures need to be in line with evidence regarding effective intervention modes for the population (so-called general responsivity), in the case of criminal offenders, CBT-based approaches seems to be most effective. In addition, the responsivity principle asserts interventions need to be adapted to the specific individual's needs (specific responsivity), which may be influenced by for instance concentration problems or the level of motivation.

One large-scale single study evaluation from England and Wales, however, demonstrated a small but significant increase in recidivism after attending treatment program (Mews, Di Bella, \& Purver, 2017), thus yielding further debates (Lösel et al., 2020). The problems regarding evidence are partly due to methodological limitations related to ethical and practical obstacles when conducting randomized controlled trials (RCTs) within the prison and probation setting (Lösel et al., 2020; Marshall \& Marshall, 2007) and the generally low base rates of recidivism (Hanson, 2014). A majority of sexual crimes goes undetected (DeLisi et al., 2016; Drury, Elbert, \& DeLisi, 2020; Westfelt, 2008); thus, conclusions about recidivism drawing on verdicts may not be valid (Scurich \& John, 2019). Accordingly, there is a need to explore different aspects of treatment outcomes for this population. Scholars

\footnotetext{
'Department of Sociology, Center for Social Work (CESAR), Uppsala University, Sweden

Corresponding Author:

Stina Lindegren, Center for Social Work (CESAR), Department of Sociology, Uppsala University, Box 632, 75I 26 Uppsala, Sweden.

Email: stina.lindegren@soc.uu.se
} 
highlight the need for research using other types of outcome measurements in addition to the traditional crime statistics, such as behavioral change within treatment (Hanson, 2014; Harkins \& Beech, 2007; Jung \& Gulayets, 2011; Levenson \& Prescott, 2014; Marshall, Marshall, \& Olver, 2017). One way is to examine outcomes in terms of change in criminogenic needs, or dynamic (changeable) risk factors, using pre- and posttest designs. In this article, I present a study utilizing this design, with the unique combination of therapists' ratings and participants' psychometric tests, to examine the feasibility of a sexual offender treatment program within a prison and probation population of individuals convicted of a sexual offense (ISO) in Sweden.

\section{Criminogenic Needs}

Criminogenic needs refer to dynamic factors related to the risk of recidivism, that is, factors that are changeable and therefore should be targeted in offender treatment programs (Bonta \& Andrews, 2017; Mann et al., 2010). There is substantial empirical evidence for the risk factors (Bonta, Blais, \& Wilson, 2014; Eisenberg et al., 2019; Gutierrez, Wilson, Rugge, \& Bonta, 2013; Olver, Stockdale, \& Wormith, 2014; Wooditch, Tang, \& Taxman, 2014), often referred to as the Central Eight (Bonta \& Andrews, 2017). The Central Eight include antisocial history, antisocial personality pattern, pro-criminal attitudes, pro-criminal associates, substance abuse, family/marital deficits as well as deficits regarding school/work and leisure/recreation. How are these risk factors addressed in rehabilitation, or treatment programs, for individuals convicted of an offense? A comprehensive antisocial history, including early onset of rule-breaking behaviors, implies higher risk of recidivism, suggesting such individuals are in need of intensive rehabilitative measures (however, it should be noted this specific risk factor is static rather than dynamic, in the sense that a history cannot change.) Antisocial personality traits can be targeted for instance by skills training to enhance impulse control. Pro-criminal attitudes, such as neglecting the consequences of criminal behaviors, should be challenged in treatment and the individual will need help to develop a social network of prosocial peers, instead of associates endorsing and reinforcing criminal behaviors. Furthermore, rehabilitation needs to include support for substance abuse and measures to ensure a stable work situation. Dysfunctional relationships may be the result of communication skill deficits, which can be addressed in treatment as well as helping the individual in taking steps to find or develop meaningful and prosocial leisure activities. The Central Eight risk factors are of relevance in preventing recidivism in general crimes as well as sexual crimes. However, there are additional risk factors, specific for re-offense in sexual crimes. These include, among others, hypersexuality, intimacy deficits (Hanson \& Morton-Bourgon, 2005), and locus of control (Fisher, Beech, \& Browne, 1998). The Central Eight risk factors were examined in this study by therapist ratings. The participants' self-reports addressed the three specific risk factors stated before. For compliance reasons, filling out three questionnaires was deemed an appropriate amount for participants; hence, it was not feasible to investigate all Central Eight risk factors from a participant's perspective. Since treatment components addressing problematic sexual behaviors have been especially developed in the treatment program studied, Sex Offender Program with an Individual Focus (SEIF), and there is a paucity of studies examining treatment change in this regard, one questionnaire targeted hypersexuality. Improving relationship skills and intimacy deficits is a central part of SEIF, whereas relationship styles were selected as the second relevant measure. Furthermore, an increase in internal locus of control is associated with treatment success over a range of dynamic risk measures (Fisher et al., 1998). In addition, research suggests facilitation of internal locus of control enhances responsivity (D'Orazio, 2017) (an important aspect of the RNR-model, implemented in SEIF); hence, the third treatment change measure of choice was locus of control. Although these three change measures each are relevant regarding both risk of sexual re-offense and the relevance in relation to SEIF, their interconnectedness has not been very well examined in the existing literature.

\section{Hypersexuality}

For decades, sex offender treatment scholars have engaged in the study of effective interventions to alter problematic sexual behaviors related to crime; however, research have focused primarily on sexual deviance, such as pedophilia (Crolley, Roys, Thyer, \& Bordnick, 1998; Marshall et al., 2016). During the last decade, hypersexuality has emerged as an important criminogenic need, yet understudied, in terms of possible treatment impact.

Hypersexual disorder, or sometimes referred to as sexual pre-occupations or sex addiction, is a controversial and complex concept, both regarding definition and appropriate measurements (Grubbs et al., 2020; Kingston, 2016), and an established definition is lacking (Kingston \& Firestone, 2008; Walters, Knight, \& Långström, 2011). Hypersexual disorder was rejected for the Diagnostic and Statistical Manual of Mental Disorders (DSM-5) classification system of psychiatric diagnoses due to the uncertain scientific evidence (Kafka, 2014). However, the diagnosis compulsive sexual behavior disorder has been accepted in the forthcoming version of the International Classification of Diseases 11th Revision (ICD11), scheduled for implementation in 2022. Compulsive sexual behavior disorder is defined as:

A persistent pattern of failure to control intense, repetitive sexual impulses or urges resulting in repetitive sexual behaviour. Symptoms may include repetitive sexual activities becoming a central focus of the person's life to the point of neglecting health and personal care or other interests, activities, and responsibilities; numerous unsuccessful efforts to significantly reduce repetitive 
sexual behaviour; and continued repetitive sexual behaviour despite adverse consequences or deriving little or no satisfaction from it. (World Health Organization, 2021)

According to Kingston (2016), there is agreement on the central features of what I hereinafter will refer to as hypersexuality, which include the occurrence of sexual fantasies, impulses, and behaviors that are repetitive and persistent and result in negative social, emotional, physical, or legal consequences, such as sexual crimes. These fantasies and behaviors can be either normophilic or paraphilic (Kingston, 2016); however, empirical studies have demonstrated hypersexuality is strongly associated with paraphilic interests (Långström \& Hanson, 2006). Prevalence in the general population is estimated as being approximately 3-6\% (Black, 2000); however, the numbers vary greatly between studies (Grubbs et al., 2020). Among the ISO population, the corresponding numbers range between 12\% and 40\% (Kingston \& Bradford, 2013; Marshall $\&$ O'Brien, 2012). Despite the confusion regarding the different concepts, hypersexuality is a significant clinical problem, and one of the strongest predictors of recidivism in sexual crimes among ISOs (Hanson \& Morton-Bourgon, 2005; Kingston \& Bradford, 2013). Zapf, Greiner, \& Carroll (2008) suggest that hypersexuality and the risky sexual behaviors often associated with this may serve as a strategy to regulate attachment needs. Hence, research indicates that the inability to control sexual impulses and using sex as coping may increase the risk of sexually coercive behaviors or non-consensual sexual acts. Therefore, hypersexuality is of relevance in sexual offender treatment. According to a recent systematic review on the last 25 years of research, conducted by Grubbs et al. (2020), there is "a virtual absence of high-quality treatment-related research published within this time frame" (p. 1). There is however some evidence and several studies suggesting that psychosocial as well as medical treatment may be effective (Grubbs et al., 2020; Hallberg et al., 2019; Hook, Reid, Penberthy, Davis, \& Jennings, 2014; Kjellgren, 2019; Landgren, Malki, Bottai, Arver, \& Rahm, 2020; Lewis, Grubin, Ross, \& Das, 2017; Lösel \& Schmucker, 2005; Malandain, Blanc, Ferreri, \& Thibaut, 2020; Miles, Cooper, Nugent, \& Ellis, 2016; Savard et al., 2020; Wilson \& Fischer, 2018; Winder et al., 2018). Nonetheless, research regarding psychological treatment specifically for a convicted population is lacking.

\section{Locus of Control}

Individuals who place responsibility for their behaviors on external factors generally have an increased risk of relapse in the problematic behaviors targeted in psychosocial interventions (Craig, Franklin, \& Andrews, 1984). In sexual offender treatment programs, participants are encouraged to take responsibility for their future by formulating plans and taking actions to ensure a prosocial lifestyle (Marshall \& O'Brien, 2013), and locus of control constitutes a criminogenic need (Fisher et al., 1998) commonly addressed in these treatments (McAnena,
Craissati, \& Southgate, 2016). McAnena et al. (2016) cites Rotter (1966) when describing locus of control as a concept that "represents the extent to which an individual perceives their behavior and/or events in their life as being within their own control or that of some external force, for example, fate, luck, or powerful others" (McAnena et al., 2016, p. 95). Furthermore, they conclude that individuals externalizing "therefore feel themselves to be passive agents in their lives, and that events and consequences are outside their control, while those with an internal locus of control feel empowered to control events and outcomes in their lives." (p. 95). External locus of control, i.e., the perception of not being the agent in one's life, is associated with violent and sexual re-offense, and studies have demonstrated treatment can impact ISOs' locus control (Fisher et al., 1998; Mandeville-Norden, Beech, \& Hayes, 2008; Olver, Nicholaichuk, \& Wong, 2014), including online offenders (Gillespie et al., 2018). The proposed links to sexual offending include locus of control as a mediating factor between an individual's own sexual abuse victimization in childhood and later offending as well as its association with impulsivity, thus, that sexual offending may serve as a mean to regain a sense of control (McAnena et al., 2016).

\section{Attachment}

Although debated, intimacy deficits and problematic intimate relationships are often proposed to constitute risk factors for relapse in sexual crimes (Hanson \& Morton-Bourgon, 2005; Mann et al., 2010; Martin \& Tardif, 2014; Wielinga, Margeotes, \& Olver, 2021). There is a suggested connection between those risk factors and attachment. The hypothesis proposed for this link is that insecure attachment leads to intimacy deficits, which ISOs try to compensate through sexual coercion and deviant sexual behavior (Bushman, Baumeister, \& Phillips, 2001; Marshall, 2010; Marshall \& Marshall, 2016; Martin \& Tardif, 2014; Ward, Hudson, \& Marshall, 1996). Attachment theory, developed by Bowlby (1970, 1973), describes how infants interact with attachment figures, forming so-called internal working models, which impact later relationships. It has been suggested that adult attachment styles are malleable and possibly influenced by relationship-specific experiences (Klohnen, Weller, Luo, \& Choe, 2005). Empirical research supports the idea that psychotherapy can influence attachment, thus, contributing to the development of a secure attachment in individuals having insecure attachments (Fonagy et al.,1995 as cited in Broberg, Risholm Mothander, Granquist, \& Ivarsson, 2008; Levy et al., 2006). Frequency, duration of therapy, and quality of the therapeutic alliance appear to be important factors (Parish \& Eagle, 2003). ISOs, to a higher extent, are insecurely attached compared to the general population and in comparison to other offenders (Lyn \& Burton, 2004; Marsa et al., 2004; Marshall \& Marshall, 2010; Martin \& Tardif, 2015; Ogilvie, Newman, Todd, \& Peck, 2014; Smallbone \& Dadds, 2000; Smallbone \& 
McCabe, 2003; Ward et al., 1996). However, the literature on whether treatment for ISOs actually alter attachment styles is scarce; only one such study was found in the literature search. Grady, Swett, \& Shields (2016) conducted a study with incarcerated, adult males attending the Sex Offender Accountability and Rehabilitation program (SOAR) in North Carolina, USA, using Relationship Scale Questionnaire (RSQ 2-factor) (Griffin \& Bartholomew, 1994) and Adult Attachment Scale (AAS) (Collins \& Read, 1990). Results showed a significant decrease in scores for the anxiety dimension on attachment style but no change regarding the avoidant dimension, posttreatment. The study did not examine if the change in attachment scores was related to other outcomes, such as subsequent re-offending. Hence, although a lot of research has been conducted on attachment issues within the ISO population, research about treatment impact on attachment styles is still needed.

In summary, criminogenic needs relevant for the ISO population have undergone extensive investigation; however, there are still gaps where examining within-treatment change in such needs can enhance knowledge on treatment impact.

\section{Method}

\section{Research Question and Hypotheses}

The research question guiding this study was: Is there change in criminogenic needs after participation in the Swedish sexual offender treatment program called Sex Offender Program with an Individual Focus (SEIF)? The following hypotheses were tested.

Hypothesis 1: Participants in SEIF will exhibit a statistically significant reduction in hypersexuality posttreatment compared to pretreatment.

Hypothesis 2: Participants in SEIF will exhibit a statistically significant reduction in external locus of control posttreatment compared to pretreatment.

Hypothesis 3: Participants in SEIF will exhibit a statistically significant reduction in levels of anxiety as well as avoidance in their attachment styles posttreatment compared to pretreatment.

Hypothesis 4: Participants in SEIF will exhibit statistically significant higher levels of function regarding criminogenic needs, according to therapist ratings of treatment progress, posttreatment compared to pretreatment.

\section{Description of the Intervention}

The study was conducted during the pilot run of a new national sexual offender treatment program in Sweden: SEIF, which is manualized (but flexible), based on cognitive behavioral therapy, and adherence to the RNR-model (Bonta \& Andrews, 2017;
Kriminalvården Swedish Prison \& Probation Service, 2019). The main objective of the program is to reduce the risk of sexual re-offending. The program is delivered by the Swedish Prison and Probation Service, by approximately 80 therapists nationwide, in group-format or individually, to incarcerated ISOs and those on probation or parole. The decision regarding group or individual format is based on both practical circumstances and participant's characteristics in relation to group dynamics. Most probation offices deliver SEIF individually due to shorter sentences and lack of appropriate amount of participants, whereas group-format is the most common mode of intervention in the prison setting. Moreover, some personality traits may contribute to the use of individual format. Complementary individual sessions are offered when necessary, for example, when addressing sexual deviation. Furthermore, all participants who enter SEIF in prison attend booster sessions during their parole. Sessions in group-format are 3 hours long and held 2 days a week in prison and once a week at the probation office, respectively. Individual sessions are generally held once a week and are 60-90 minutes long. Recommended treatment intensity is $80-250$ hours in group or $25-100$ hours individually, depending on the specific client's risk and need assessment, in accordance with the RNR-model. In general, SEIF is accessible for all convicted ISOs, including those who deny their crime despite convictions and female sex offenders. However, it is noteworthy that there were no female participants among the first 99 SEIF-participants who were asked to join this study.

The first phase of SEIF contains individualized assessment elements such as a forensic case formulation (Sturmey \& McMurran, 2011) (see figure 1). In SEIF, the case formulation consists of theoretically derived explanations for the origin and possible discontinuation of the individual criminal behavior, that is, hypotheses regarding why and how the problematic behaviors and circumstances, resulting in a sexual crime, have occurred and evolved over time, as well as hypotheses about which treatment components may facilitate the reduction of such behaviors or high-risk situations. Furthermore, the case formulation contains a detailed treatment plan. The case formulation is co-constructed with each participant individually during the initial phase, aiming for collaboration and transparency regarding assessments, treatment hypotheses and planning of treatment components (Kriminalvården Swedish Prison \& Probation Service, 2019). Furthermore, assessments of individual criminogenic needs are conducted using the Therapist Rating Scale-2 (TRS-2) (Marshall \& Marshall, 2009), as well as an examination of the participant's valued direction (Hayes et al., 1999), i.e., the formulation of personal long-term process goals, inspired by Acceptance and Commitment Therapy.

The second phase comprises work directed at individual treatment needs, revolving around themes concerning relationships, sexuality, (pro-criminal) attitudes, and emotions. Treatment components available in the manual are utilized with flexibility and include exercises based on traditional CBT techniques such as functional analysis, cognitive restructuring, self-regulation, role-play, mindfulness, and home assignments, 


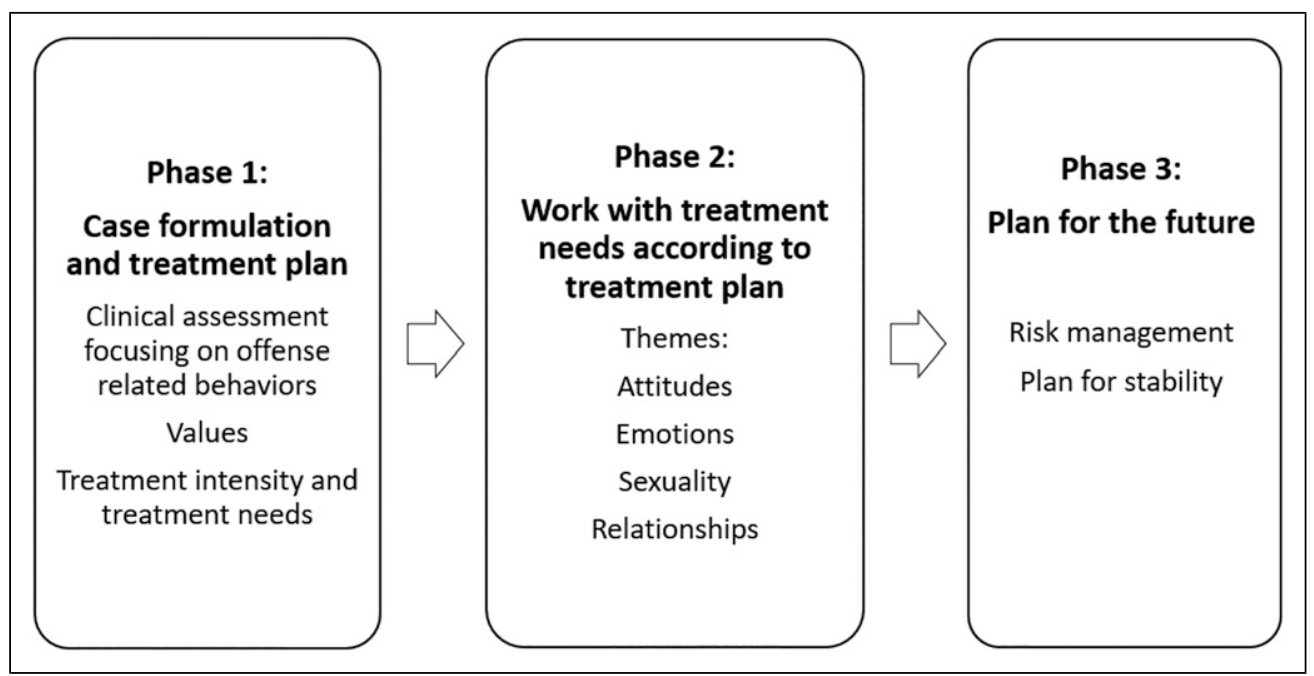

Figure I. Description of sex offender program with an individual focus (SEIF): content of the three treatment phases. Note. Lätth (2019), modified.

among others. The therapeutic alliance and process is emphasized in SEIF and the therapist style include being non-judgmental, warm, and empathetic, in accordance with existing evidence (Ross et al., 2008; Marshall, 2005). The responsivity principle guides adjustments in the delivery of treatment where for instance sessions with hyperactive participants may include more breaks etcetera. During the last phase of SEIF, the participant establishes a plan for the future, including risk management (Kriminalvården Swedish Prison \& Probation Service, 2019). Treatment progress defined as change in criminogenic needs, or reduction of risk factors, is rated midways through treatment and in the final phase using the TRS-2, which assists the therapist in assessing treatment duration.

\section{Study Design and Sample}

To test the research question and hypotheses, the study employed a pretest-posttest design to examine within-group change in criminogenic needs within a group of adult male, incarcerated or on probation, ISOs who completed SEIF, using self-report scores from three psychometric tests and therapist ratings. The combination of measurements contributes to answer the research question from different angles, enhancing validity. The study design, however, did not include a control group, which limits validity; these matters are further discussed in the discussion section of this article. Eligibility criteria for inclusion in the study were equivalent to the ones for inclusion in SEIF. The study sample comprised the first cohort of participants in the pilot run of SEIF: 99 male ISOs in five prisons and 14 probation offices all over Sweden were asked to volunteer for the study.

\section{Data Collection}

The empirical material comprises two parts: participants' preand posttreatment self-reports and the therapists' pre- and posttreatment ratings and were collected between August
2017 and February 2019, initiated for an internal pilot evaluation. A SEIF coordinator kept record of the first cohort of participants in SEIF, the 99 individuals comprising the study sample, and instructed therapists regarding data collection. The therapists who delivered SEIF to these participants conducted the therapist ratings, TRS-2, using a pseudonymized electronic document. Moreover, the therapists informed coordinating staff within the Prison and Probation Service, i.e., a probation officer or case manager, which individuals who were included in the study and coordinating staff in turn administrated participants' pre- and posttests. Tests were filled out individually by pen and paper. The tests included a personal code securing pseudonymity and enabling matching of the pretest with the same participant's posttest. During the data collection and analysis phase, it became evident that there was quite a large data loss, which I will address in the discussion (see figure 2 for details regarding data collection).

\section{Ethical Approval}

The study was initiated during the author's master studies in social work and is now part of a larger doctoral project at Uppsala University investigating ISOs' experiences of treatment and support for problems related to sexual offending. Institutional ethics approval was obtained from the Prison and Probation Service as well as from the University responsible for the master's program (Ersta Sköndal Bräcke University College). The study adhered to the basic ethical guidelines of good research practice, produced by the Swedish Research Council (2017). From the start and throughout the study, all data were pseudonymized; thus, the identity of the participants was unknown. Participation in the study was voluntary and included informed consent, with awareness of the risk of participants feeling pressured to participate, due to the inherent power asymmetry in the Prison and Probation context. 


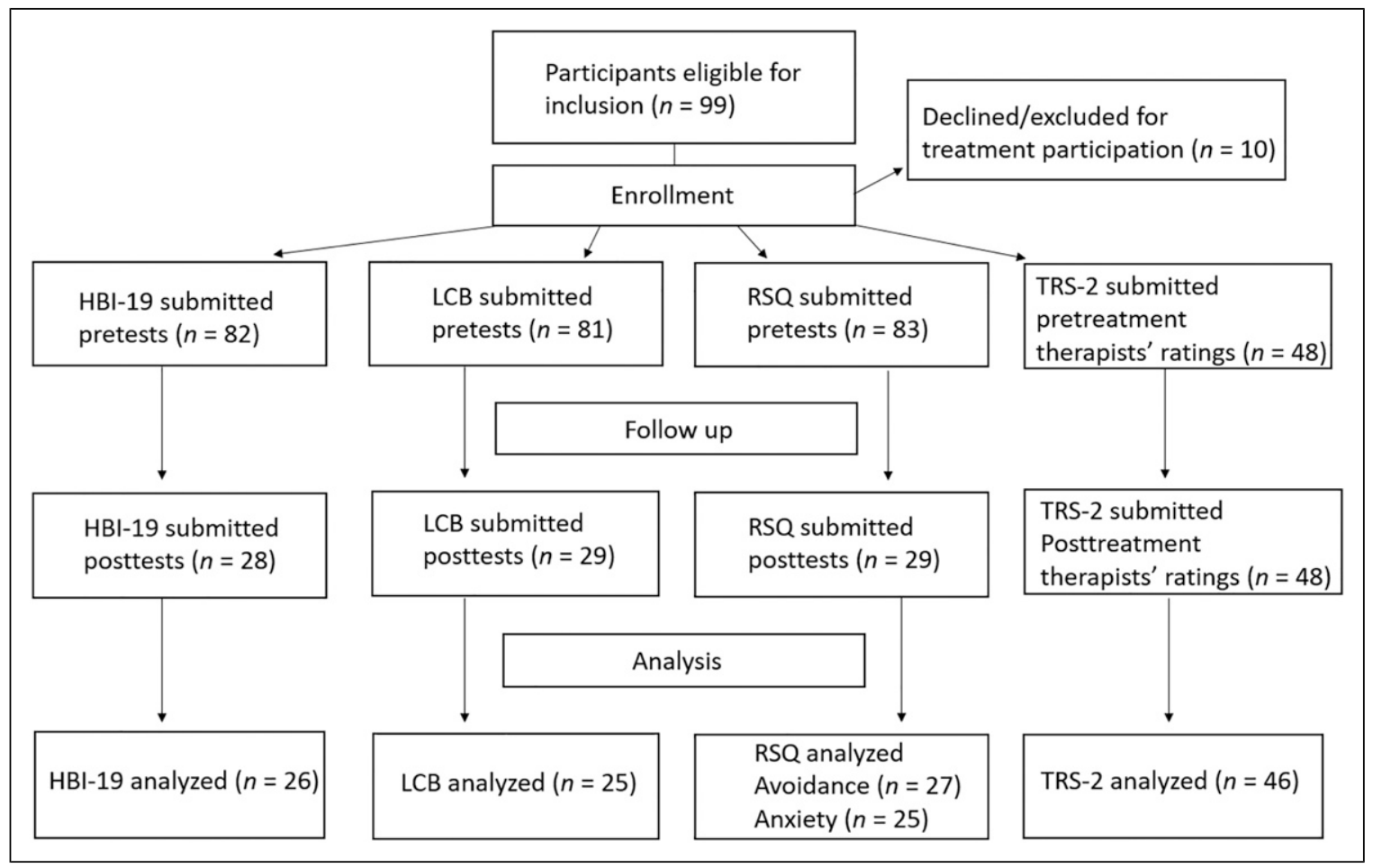

Figure 2. Flowchart illustrating the data collection of participants' self-reports and therapists' ratings.

\section{Psychometric Measures and Rating Scale}

The Hypersexuality Behavior Inventory-19 (HBI-19) was utilized to measure participants' perceived problems regarding hypersexuality. It comprises 19 items, total score is 95 points, ranging from 19 to 95 , using a five-point Likert scale where there is no reversed coding of items (Reid, Garos, \& Carpenter, 2011). The domains include inability to control sexual fantasies or behaviors, using sex as a coping strategy, and inability to stop such behaviors despite negative consequences. The HBI-19 has demonstrated a high convergent validity in relation to other psychometric tests measuring hypersexuality and related concepts. The internal consistency for the scale overall has been shown to be high with a Cronbach's alpha at .96, replicated in another study (Reid et al., 2012). Several reviews conclude that the HBI-19 is a reliable psychometric test to measure hypersexuality, within both clinical and non-clinical samples (Marshall \& Briken, 2010; Montogomery-Graham, 2016; Stewart \& Fedoroff, 2014). Suggested cutoff is at 53 points; thus, scores at and above this indicate clinically significant problems (Reid et al., 2011). Nevertheless, others argue cutoff cannot yet be determined (Böthe et al., 2019).

To measure participants' locus of control, the Locus of Control of Behavior Scale (LCB) was employed (Craig et al., 1984). The test includes 17 items, total score is 85 points, ranging from 0 to 85 , using a six-point Likert scale and reversed coding for item $1,5,7,8,13,15$, and 16 . Reliability measurements have demonstrated acceptable internal consistency with a Cronbach's alpha of .79 regarding all items. Its construct validity has been examined through correlation measurements with the resembling Rotter's I-e Scale, where the correlation coefficient was .67 for men and .66 for women (Craig et al., 1984).

Attachment was measured using the Relationship Scale Questionnaire (RSQ), developed by Griffin and Bartholomew (1994), comprising 30 items concerning aspects of relationships, using a five-point Likert-scale. The RSQ can be analyzed in several ways. Analysis using the four attachment categories, secure, fearful, preoccupied, and dismissing (Bartholomew \& Horowitz, 1991) have been shown to range between a Cronbach's alpha of .41-.70 in reliability measures, indicating limited internal consistency. For this reason, and because of the limited sample, it was decided to instead analyze RSQ employing the 2-factor loading of the anxious and avoidant dimensions. The 2 -factor loading of RSQ is based on the model presented by Simpson, Rholes, \& Nelligan (1992) and includes items $11,18,21,23$, and 25 for the anxiety dimension and items 10,12,13,15, 20,24, 29, and 30 for the avoidant dimension. Kurdek (2002) demonstrated this as being a more reliable approach, with the anxiety scores yielding a Cronbach's alpha of .83 and the avoidant scores .77 . Total score for the anxiety dimension is 25 points, ranging from 5 to 25, no reverse coding. Total score for the avoidant dimension is 40 points, ranging from 8 to 40 , reversed coding for items 10, 15, and 30 .

The Therapist Rating Scale-2 (TRS-2) (Marshall \& Marshall, 2009) is an assessment tool for treatment needs and treatment progress and is based on research on 
criminogenic needs within the ISO population. Nonetheless, the items are also related to dynamic risk factors for general crimes, the Central Eight (Bonta \& Andrews, 2017). Each item, or criminogenic need, yields a score of 1-4 on two categories of functioning: intellectual understanding and acceptance/demonstration, where the first indicates cognitive progress and the second observed behavioral change (Marshall \& Marshall, 2009). Total score for the TRS-2 is 80 points, ranging from 20 to 80 where a total score of 50 points indicate attainment of the treatment goals and scores below 45 points indicate further need of treatment. Corresponding numbers for each of the 10 items is a total score of eight points, ranging from 2 to 8 where a total score of three points on each category, that is, in total six points, is indicative of attainment of the treatment goals for that specific criminogenic need. The TRS-2 is a fairly new instrument, and studies suggest that its psychometric properties are promising; moreover, it seems to be a comparatively valid predictor for recidivism in sexual crimes. The TRS-2 has a high inter-rater reliability and high internal consistency, with a Cronbach's alpha of .97 for the total score, .96 for the intellectual understanding category, and .94 for the acceptance category (for references, see Marshall \& Marshall, 2009).

\section{Data Analysis}

Data were analyzed using IBM SPSS Statistics 22. To test change in criminogenic needs, comparative analyses were conducted using non-parametric tests for paired groups using the Wilcoxon Signed Rank Test (Pallant, 2016). Mann Whitney-U tests were conducted for comparisons between independent sub-groups (participants on probation or in prison). The choice of non-parametric tests was due to several outliers and the limited sample size. To measure the size of significant changes, effect size was calculated (Cohen, 1988). Mean score was added for four tests on the LCB and three on the HBI-19 where only one value was missing, in order to enlarge the sample of matching pairs of tests. Cases missing one test (pre- or post-) were excluded, as well as cases with two or more missing values in either of the tests. Pseudonymized descriptive statistics of the 99 participant's characteristics were obtained from the Prison and Probation Service.

\section{Results}

\section{Participants}

The oldest participant was 81 years old, the youngest 19, and the mean age was 39 years. Forty-five individuals participated during parole or probation and 54 when incarcerated. Included prisons represented all security levels: low, medium, and high security. The most common risk assessment for the participants, according to the Swedish Prison and Probation Service's own risk assessment tool, was low risk for recidivism (see Table 1).
The most common offense in the current sentence was sexual molestation (a minor offense against adults or children, such as inappropriate touching or indecent exposure) (see Table 2). It is noteworthy however that a majority of participants $(n=62)$ had several sexual offenses under the same sentence. Data of victim characteristics were not available; however, the participants were convicted of sexual crimes against adults as well as minors (some offenses in the second category are marked by the use of the term minor or child). Sixteen participants had one or several (up to 11) prior convictions and seven of the participants were previously convicted of sexual crimes. The most common offense in prior convictions was physical assault or unlawful threat (see Table 3).

Data describing treatment intensity for all 99 participants were not available; however, data from the first 33 participants who finished SEIF during the study period show that on average, treatment intensity was 53 hours in total for participants on probation ( $M=87$ hours for group-format and $M=$ 44 hours for individual format). For incarcerated participants, treatment intensity was 142 hours in total on average $(M=$ 152 hours for group-format and $M=58$ hours for individual format). The participant, of these 33 individuals, with lowest treatment intensity had 25 hours treatment in total and the one with highest intensity had 205 hours of treatment in total. As previously discussed regarding intervention format, the majority of probationers in the study received individual treatment and the majority of incarcerated participants received group treatment.

The 38 therapists participating in the study were all employed at the Prison and Probation Service. They had different educational backgrounds: 13 were licensed psychologists, nine had a bachelor's degree in social work (four of them with additional basic psychotherapy education/training), nine had a bachelor's degree in behavioral science, and the remaining seven had various bachelor's degrees within the social sciences. Therapists who did not have basic psychotherapy training or a psychologist license received 12 weeks of basic training in cognitive behavioral therapy, before the specific SEIF training, described later. Specific experience of sexual offender treatment ranged between $<1$ and 9 years, with an average of 3.99 years. The average experience of any criminal offender treatment program was 9.27 years, ranging from $<1$ to 23 years.

The therapists engaged in 3 weeks of SEIF therapist group training, which included the theoretical foundations for SEIF, manual guidance, and skills training (experienced therapists who had previously worked with sexual offender treatment received 4 days of training). There was also specific training in working with sexual risk factors. In addition, the therapists completed an, on average $2-3$ years, individual certification process. During this time, thus, the study period included, all therapists recorded their sessions, by audio or video, and they were under supervision of licensed psychologists, thus controlling for fidelity to the SEIF manual. 
Table I. Results: participants. Assessed risk for recidivism in general and sexual crimes $(n=99)$.

\begin{tabular}{lllll}
\hline & Low risk & Medium risk & High risk & Not assessed \\
\hline Recidivism risk general crime & $67 \%$ & $26 \%$ & $7 \%$ & $0 \%$ \\
Recidivism risk sexual crime & $49 \%$ & $25 \%$ & $25 \%$ & $1 \%$ \\
\hline
\end{tabular}

Table 2. Results: participants. The most common offenses in the current sentence for the study sample $(n=99)$.

\begin{tabular}{lc}
\hline & $\begin{array}{c}\text { Number of participants with } \\
\text { offense in current sentence }\end{array}$ \\
\hline Sexual molestation & 34 \\
Child rape & 27 \\
Rape & 19 \\
Child pornography & 15 \\
Child sexual abuse & 12 \\
Aggravated child pornography & 7 \\
Exploitation of a minor for the & 7 \\
purpose of sexual posing & 6 \\
Aggravated rape & \\
\hline
\end{tabular}

Table 3. Results: participants. The most common offenses in prior convictions for the study sample $(n=16)$.

\begin{tabular}{lc}
\hline & $\begin{array}{c}\text { Number of offenses in prior } \\
\text { convictions }\end{array}$ \\
\hline Assault (physical) & 12 \\
Unlawful threat & 12 \\
$\begin{array}{l}\text { Obstructing the course of } \\
\text { justice }\end{array}$ & 11 \\
Theft & 10 \\
Robbery & 9 \\
Assault or threat against an & 9 \\
official & 9 \\
Drug offense & 9 \\
Vehicle theft & 7 \\
\hline
\end{tabular}

\section{Hypersexuality (HBI-19)}

The lowest possible score on HBI-19 is 19 points, and the total score is 95 points, where low scores indicate fewer problems related to hypersexuality. When analyzing all complete pretests, 11 participants $(15 \%)$ scored at proposed cutoff or above $(\Rightarrow$ 53, $M d=25, M=31.14, S D=16.14, n=72$ ), thus, indicating clinically significant hypersexual problems. According to hypothesis 1, participants in SEIF would exhibit a statistically significant reduction in hypersexuality posttreatment compared to pretreatment. A comparison using the Wilcoxon Signed Rank Test for paired groups, of participants with complete preand posttests $(n=26)$, demonstrated a significant decrease in hypersexual problems posttreatment ( $p=.034$, two-tailed), with a small to medium effect size $(r=.29)$. The median score pretreatment was $30(M=31.12, S D=11.83, n=26)$ and posttreatment $24(M=27.92, S D=15.07, n=26)$. Thus, hypothesis 1 was supported and the null hypothesis was rejected. As demonstrated in figure 3, participants who experienced most problems regarding hypersexuality were also the ones with a larger decrease in scores. Since it is conceivable that hypersexual behaviors would decrease as a natural consequence while incarcerated, because of limited access to sexual stimuli, a comparison was made using Mann Whitney-U Test for independent groups between the two sub-groups in the study sample, i.e., participants on probation and participants in prison. This test did not demonstrate any significant difference between the probation and prison group, neither between pretreatment scores of each group nor between posttreatment scores. Hence, the reduction of hypersexual problems is not attributable to the sub-group of participants in prison alone, indicating that other factors beyond the restricted prison context, possibly SEIF, contributed to the changes identified.

\section{Locus of Control (LCB)}

According to hypothesis 2, participants in SEIF would exhibit a statistically significant reduction in external locus of control posttreatment compared to pretreatment. A reduction of scores on LCB represents a decrease in external locus of control, or an increased internal locus of control, thus an indication of change in the intended direction. Mean score at pretreatment was $28.68(S D=10.43, n=25)$ and at posttreatment $26.12(S D=14.32, n=25)$. A comparison using the Wilcoxon Signed Rank Test for paired groups demonstrated there was no statistically significant difference ( $p>.05$, twotailed) between the pre- and posttreatment scores, thus, hypothesis 2 was not supported and the null hypothesis could therefore not be rejected. However, there was a tendency for change with a small effect size $(r=.19)$, where the median score at pretreatment was 28 and at posttreatment $22(n=25)$. This equals a $21 \%$ reduction of the median score. Seventeen of the participants (68\%) lowered their scores posttreatment; thus, they experienced an increase in internal control. For six participants (24\%), there was an increase in external locus of control.

\section{Attachment (RSQ)}

According to hypothesis 3, participants in SEIF would exhibit a statistically significant reduction in levels of anxiety as well as avoidance in their attachment styles posttreatment 


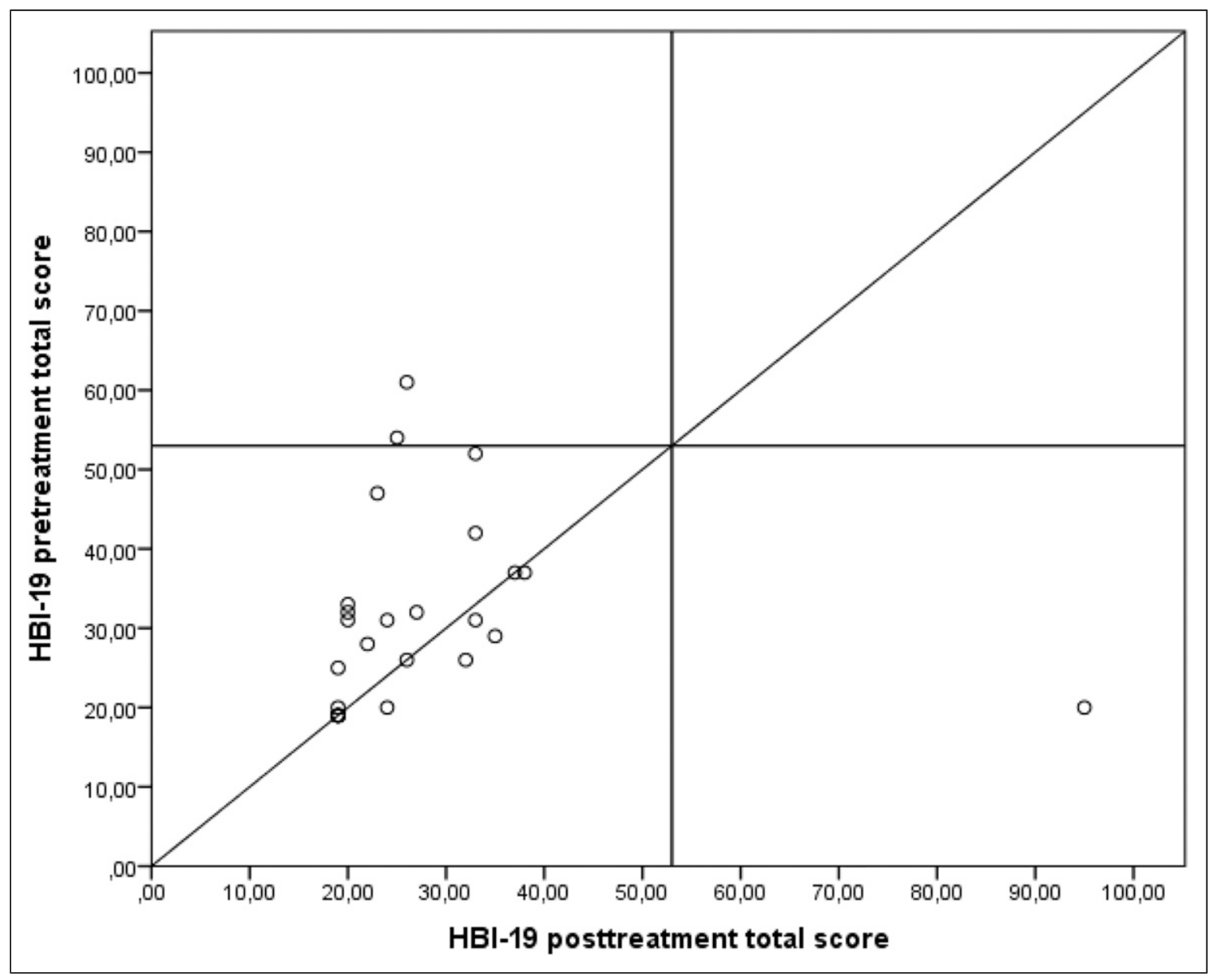

Figure 3. Results: hypersexuality pre- and posttreatment.

Note. This figure demonstrates comparison of participants' total scores on the $\mathrm{HBI}-19$, where the $y$-axis reads the pretreatment scores and the $x$-axis posttreatment scores of each participant $(n=26)$. Participants above the diagonal reference line have lower scores posttreatment, thus indicating change in intended direction. The vertical and horizontal lines mark the proposed cutoff at 53 points.

compared to pretreatment. Low scores on the RSQ are preferred, thus indicating low levels of anxiety or avoidance in the individual's attachment style. There was no significant difference ( $p>.05$, two-tailed) on either one of the dimensions between the pre- and posttreatment scores when conducting a Wilcoxon Signed Rank Test for paired groups. The mean score for the anxiety dimension was $10.80(S D=3.46, n=25)$ and median 10 pretreatment, respectively, $11.28(S D=5.23, n=$ 25 ) and median 11 posttreatment. For the avoidance dimension, the mean was $20.74(S D=5.41, n=27)$ and median 20 pretreatment, respectively, $19.78(S D=4.93, n=27)$ and median 21 posttreatment. Accordingly, hypothesis 3 was not supported and the null hypothesis could not be rejected. Participants' attachment styles did not change following treatment.

\section{Therapists' Ratings of Criminogenic Needs (TRS-2)}

According to hypothesis 4, participants in SEIF would exhibit statistically significant higher levels of function regarding criminogenic needs, according to therapist ratings of treatment progress, posttreatment compared to pretreatment. The total rating of the TRS- 2 ranges between 20 and 80 points, where a total of 50 points indicate attainment of the treatment goals. Thus, the therapist assesses the participant to have a normative function (corresponding to the levels of function expected in the general population) regarding the criminogenic needs assessed in this scale (Marshall \& Marshall, 2009). Ratings less than 45 indicate treatment should continue, given the remaining treatment needs. A Wilcoxon Singed Rank Test for paired groups demonstrated a significant change $(p<.001$, two-tailed), in total scores between pre- and posttreatment ratings with a large effect size $(r=.68)$. The mean pretreatment was $40.20(M d=41$, $S D=10.29, n=46)$ and posttreatment $51.78(M d=54, S D=$ $8.33, n=46$ ). Sixty percent of the participants were assessed to have reached the normative level of function, whereas $17 \%$ were assessed as being in need of further treatment. Pretreatment, the corresponding ratings were $20 \%$ for normative function and $63 \%$ for insufficient function, respectively. 
Table 4. Results: Therapists' ratings of change in criminogenic needs pre- and posttreatment.

\begin{tabular}{|c|c|c|c|c|c|}
\hline & $M(S D)$ & Md & Min-max & $p$ & $r$ \\
\hline I. Sense of agency & $\begin{array}{l}4.30(1.33) \\
5.20(1.03)\end{array}$ & $\begin{array}{l}4 \\
6\end{array}$ & $\begin{array}{l}2-6 \\
2-6\end{array}$ & $<.001$ & .43 \\
\hline 2. General empathy & $\begin{array}{l}4.03(1.52) \\
5.13(1.08)\end{array}$ & $\begin{array}{l}4 \\
5\end{array}$ & $\begin{array}{l}2-7 \\
2-7\end{array}$ & $<.001$ & .48 \\
\hline 3. Prosocial attitudes & $\begin{array}{l}4.82(1.52) \\
5.59(1.12)\end{array}$ & $\begin{array}{l}5 \\
6\end{array}$ & $\begin{array}{l}2-8 \\
2-8\end{array}$ & .002 & .32 \\
\hline 4. Adequate coping skills/styles & $\begin{array}{l}3.36(1.07) \\
4.88(.97)\end{array}$ & $\begin{array}{l}4 \\
5\end{array}$ & $\begin{array}{l}2-5 \\
2-7\end{array}$ & $<.001$ & .56 \\
\hline 5. Adequate intimacy skills & $\begin{array}{l}3.56(1.18) \\
4.85(1.02)\end{array}$ & $\begin{array}{l}4 \\
5\end{array}$ & $\begin{array}{l}2-6 \\
2-6\end{array}$ & $<.001$ & .52 \\
\hline 6. Positive self-esteem & $\begin{array}{l}4.04(1.23) \\
5.22(1.02)\end{array}$ & $\begin{array}{l}4 \\
6\end{array}$ & $\begin{array}{l}2-6 \\
2-7\end{array}$ & $<.001$ & .52 \\
\hline 7. Good general self-regulation & $\begin{array}{l}3.88(1.31) \\
5.13(.95)\end{array}$ & $\begin{array}{l}4 \\
5\end{array}$ & $\begin{array}{l}2-6 \\
3-8\end{array}$ & $<.001$ & .51 \\
\hline 8. Good sexual self-regulation & $\begin{array}{l}3.97(1.5 \mathrm{I}) \\
5.28(.99)\end{array}$ & $\begin{array}{l}4 \\
6\end{array}$ & $\begin{array}{l}2-6 \\
2-6\end{array}$ & $<.001$ & .49 \\
\hline 9. Understands risk factors & $\begin{array}{l}3.82(1.31) \\
5.13(1.36)\end{array}$ & $\begin{array}{l}4 \\
6\end{array}$ & $\begin{array}{l}2-6 \\
2-7\end{array}$ & $<.001$ & .48 \\
\hline 10. Quality of future plans & $\begin{array}{l}4.38(1.53) \\
5.43(1.00)\end{array}$ & $\begin{array}{l}4 \\
6\end{array}$ & $\begin{array}{l}2-8 \\
2-8\end{array}$ & $<.001$ & .42 \\
\hline
\end{tabular}

Note. This table demonstrates comparison and values pretreatment (upper line) and posttreatment (lower line) on the TRS- 2 for each of the 10 treatment needs ( $n=47$ for all treatment needs, except for number 10 where $n=46$ ).

A comparison between pre- and posttreatment scores of the whole sample regarding each of the 10 needs in the TRS2, using the Wilcoxon Signed Rank Test for paired groups, revealed there was a significant difference between pre- and posttreatment ratings for all 10 needs $(p=<.002$, twotailed), with a large effect $(r=>.50)$ for four of them and medium effect $(r=>.30)$ for the remaining six, as demonstrated in Table 4. Hence, hypothesis 4 was supported and the null hypothesis was rejected, regarding both the total score of the TRS- 2 and scores for each of the 10 criminogenic needs.

Another comparison analysis was conducted between preand posttreatment ratings of the two categories of the TRS-2 called intellectual understanding and acceptance/demonstration, where the ratings range between 10 and 40 points. A Wilcoxon Signed Rank Test for paired groups demonstrated there was a significant difference for both categories $(p<.001$, two-tailed), with a large effect size $(r=.56$ for intellectual understanding and $r=.57$ for acceptance/demonstration, respectively). The mean rating for intellectual understanding pretreatment was 21.47 ( $S D$ $=5.34, M d=22, \min =10, \max =31, n=46)$ and posttreatment $27.42(S D=4.18, M d=29, \min =13, \max =34, n=46)$. For the acceptance category, the mean rating pretreatment was 18.74 $(S D=5.23, M d=19, \min =10, \max =29, n=46)$ and posttreatment $24.36(S D=4.35, M d=25, \min =11, \max =31$, $n=46$ ).

To reach the normative (desired) level of function posttreatment, for each of the 10 treatment needs, the participant needs to reach a rating at a minimum of three points on both the intellectual understanding and acceptance category. The proportion of participants reaching this level for each treatment need in the TRS-2 is demonstrated in figure 4.

\section{Discussion and Applications to Practice}

The results of the participants' self-reports demonstrate a significant decrease in hypersexuality (small to moderate effect size), a non-significant increase in internal locus of control, but no change regarding attachment styles. In addition, the therapists' ratings demonstrated a significant decrease in all criminogenic needs (which include the Central Eight risk factors), with medium to large effect size, and $60 \%$ of the participants were assessed to have achieved the treatment goals posttreatment, according to the TRS-2. Both the therapist ratings and participants' self-reports point in the same direction, indicating the positive outcomes are valid. The main difference is that therapist ratings demonstrate change in all studied areas and with larger effects than participants' selfreports, which can be a result of therapists' confirmation bias, thus, a non-deliberate exaggeration of treatment progress.

In Sweden, there is lack of research regarding psychosocial interventions in general, although the number of studies is growing. Sundell and Åhsberg (2018) highlight the need for service providers to examine interventions in terms of potential harms and benefits. The results suggest SEIF does not appear to have negative effects (the outlier in figure 3 is most likely a result of inaccurate responses); on the contrary, the study indicates SEIF may reduce problems related to increased 


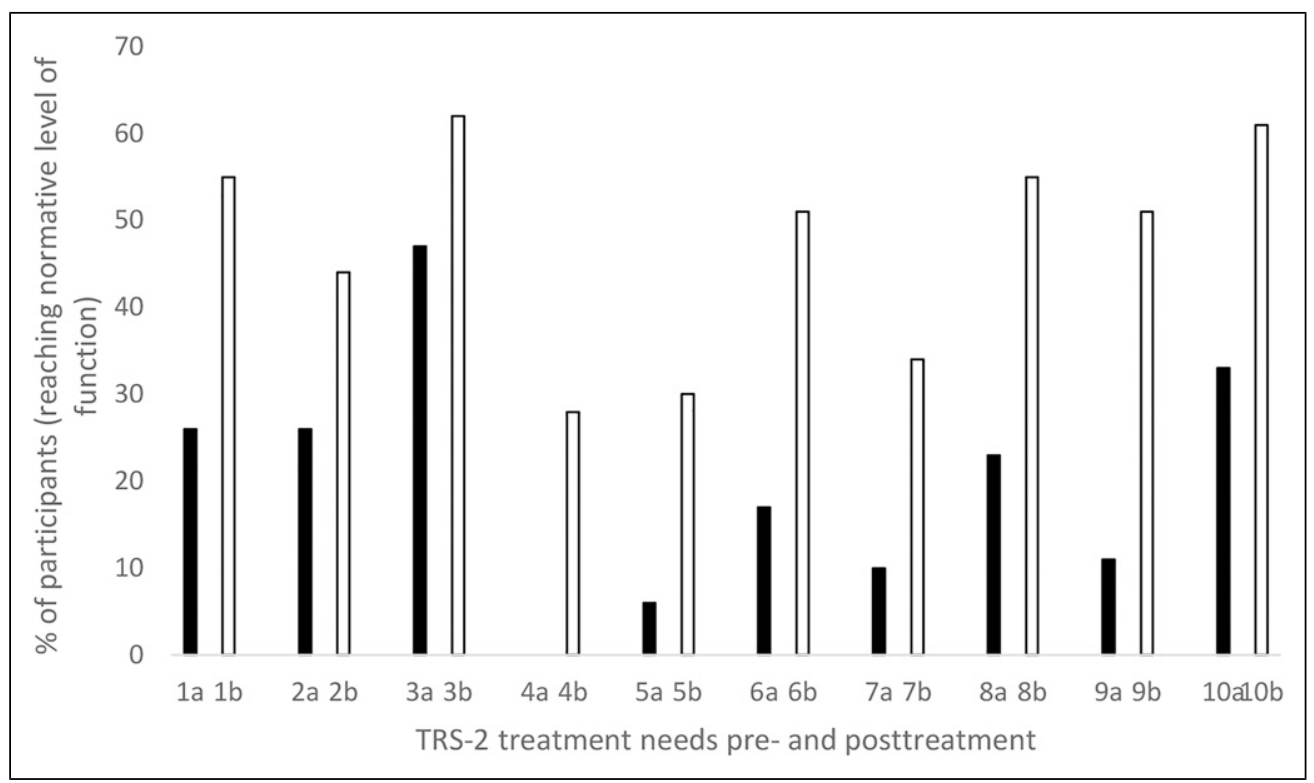

Figure 4. Results: therapists' ratings of treatment progress.

Note. This figure demonstrates comparison between pre- (a) and posttreatment (b) ratings of each treatment needs in the TRS-2. The bars represent the proportion (\%) of participants who have been rated to reach the normative level of function, that is, attainment of the treatment goals, on both intellectual understanding and acceptance/demonstration categories $(n=47$, except for treatment need I0, where $n=46)$. I. Sense of agency, 2. general empathy, 3. prosocial attitudes, 4. adequate coping skills/styles, 5. adequate intimacy skills, 6 . positive selfesteem, 7. good general self-regulation, 8. good sexual self-regulation, 9. understands risk factors, and I0. quality of future plans.

risk of recidivism, especially hypersexuality. These findings motivate further implementation of SEIF. However, this study cannot evaluate the effectiveness of the program, due to limitations as discussed later. Hence, further studies are necessary. Nevertheless, the results are in line with previous research indicating that CBT-based sexual offender programs that adhere to the RNR-model are effective (Hanson et al., 2009). The improvements demonstrated in this study can be interpreted using Bandura's concept of self-efficacy (Bandura, 1997), explaining how the participants' beliefs in their function and abilities to manage events and obstacles in their lives were strengthened by the engagement in SEIF.

The fact that the specific elements of SEIF, targeting sexual self-regulation, seem to be particularly successful, especially for participants with severe hypersexual problems, is worth noting since it is one of the strongest predictors of recidivism (Hanson \& Morton-Bourgon, 2005). This result is in line with previous studies of a non-offending population (Hallberg et al., 2019; Hook et al., 2014; Kjellgren, 2019; Miles et al., 2016; Wilson \& Fischer, 2018). Since it has been suggested that hypersexuality is dimensional, reflecting differences in degree rather than kind (Walters et al., 2011), reductions in scores of participants who, pretreatment, scored below the proposed (Reid, Garos, \& Carpenter, 2011), as well as the debated (Böthe et al., 2019) cutoff, might also be of significance. These findings are relevant to practitioners and highlight the need to focus explicitly on sexual problems for ISOs experiencing hypersexuality. Therapists in this study had special training in working with participants' sexual selfregulation and it is conceivable that such specific training is important due to the sensitive nature of this topic.

Approximately two-thirds of the participants experienced a (non-significant) increase in internal locus of control, which corresponds to the results of other studies, indicating psychological treatment can increase internal locus of control in the ISO population (Fisher et al., 1998; Mandeville-Norden et al., 2008; Olver, Nicholaichuk, \& Wong, 2014). This study also supports previous findings (employing other types of psychometric tests) that specifically CBT for ISOs can have a positive impact on internal locus of control (Jung \& Gulayets, 2011; McAnena et al., 2016). The fact that the abovementioned studies demonstrated significant effects on locus of control, in contrast to this study, might be due to a larger sample.

SEIF did not seem to have an impact on the participants' attachment styles. The only study of change regarding the attachment styles of ISOs posttreatment found in the literature review, also using RSQ 2-factor, demonstrated, in line with this study, that there was no change in avoidant attachment styles. However, the opposite was evident for the anxious dimension (Grady et al., 2016). One possible explanation for the differences may be that the treatment program in the latter study was more intensive, since frequency and duration of therapy have been suggested to be of importance (Parish \& Eagle, 2003). Another explanation is that attachment styles are developed throughout the course of life and are fairly stable in 
their nature and therefore perhaps not as easy to alter, in comparison to other treatment targets. The study of attachment in relation to stability and change, especially in the ISO population, is however very complex. Thus, conclusions should overall be drawn cautiously (see discussions in Martin \& Tardif, 2015; Martin \& Tardif, 2014).

The results from the TRS-2 show that the levels of the intellectual understanding of criminogenic needs are higher than for the acceptance/demonstration category. Hence, one might speculate whether the behavioral change is preceded by cognitive change or whether the treatment program is more effective in addressing cognitive processes than behavioral processes. Moreover, the therapist ratings (see figure 4) demonstrate that salient criminogenic needs in this study sample appear to be inadequate coping styles and intimacy skills and that it may be possible to achieve improvements in these areas with cognitive-behavioral treatment components. This can be put in relation to the participants' own perceived decrease in hypersexual behaviors; hence, improved coping and intimacy skills may reduce the need to use sex as emotion regulation, or a substitute for attachment-related needs, as well as facilitate control over excessive sexual behaviors.

It should be noted that this study does not reveal whether participants' recidivism risk was altered; furthermore, it does not show whether the changes in criminogenic needs persisted, since there was no follow-up. Previous studies have supported the use of psychometric self-reports and ratings of treatment gains as valid predictors of recidivism (Allan, Grace, Rutherford, \& Hudsonet, 2007; Beggs \& Grace, 2011; Craig, Thornton, Beech, \& Browne, 2007; Thornton, 2002), while others have not (Barnett, Wakeling, Mandeville-Norden, \& Rakestrow, 2012; 2013; Olver, Kingston, Nicholaichuk, \& Wong, 2014; Wielinga et al., 2021). However, some of these varied results may be related to the risk relevance of the construct measured (Wielinga et al., 2021). The use of selfreports in general can be questioned from a methodological standpoint, specifically those regarding attachment (Martin \& Tardif, 2014; Stirpe, Abracen, Stermac, \& Wilson, 2006). Another caution, previously mentioned, concerns the therapists' ratings in this study, which highly likely were influenced by confirmation bias and overstatements of client improvement (cf. Walfish, McAlister, O’Donnell, \& Lambert, 2012). Participants' self-reports could also reflect social desirable responding, even though this may not necessarily be the case (Fisher et al., 1998; Pham, Nunes, Maimone, \& Hermann, 2021).

Although the results indicate positive outcomes, there are several methodological limitations to this study. The study comprised a small convenience sample without a control group; hence, it cannot be ruled out that the measured change was due to other factors than the intervention and generalizability is limited. However, the ecological validity of the study is high since it was conducted in the regular setting, studying regular activities, within the Swedish Prison and Probation Service. It was unfortunately not possible to compare therapists' ratings with participants' self-reports because the material was pseudonymized and no code key existed. Another significant limitation is the large amount of missing data. Because data were pseudonymized, it was not possible to analyze potential differences between the participants who dropped out and those that completed the treatment program and/or the self-reports. Ten participants, of the initial 99, never started the treatment for different reasons. Statistics for all the SEIF-participants during the study period (not only those included in the study) demonstrate that in general, for one-third of SEIF-participants, treatment was not completed or they were transferred for different reasons. The remaining data loss, regarding the participants' self-reports, could be accounted for by those who simply did not wish to further participate in the study. In addition, some self-reports did not contain the personal code; thus, pre- and posttests could not be matched. The therapists handed in only 46 completed pre- and postratings from the TRS-2 out of a total of 99 . This might partly be due to the participants' dropout rates but also therapists' retirement, employment termination, sick and parental leave, or non-compliance because of workload or other reasons.

In future research on sexual offender treatment, it could be of relevance to look into participants' self-reports of other types of criminogenic needs demonstrated to have a high impact on recidivism, such as antisocial behaviors and general selfregulation (Hanson \& Morton-Bourgon, 2005). In addition, the risk of social desirable responding in self-report studies could be managed using, for instance, residual change scores, as demonstrated in the 18-year follow-up study of treated ISOs by Olver, Nicholaichuk, and Wong (2014) or by adding formalized risk assessment tools. In similar pilot or feasibility studies on new treatment programs, additional data could be collected, exploring the implementation process. A randomized, controlled effectiveness study of SEIF, investigating outcomes in terms of re-offense using a larger sample, is necessary. A qualitative study of SEIF on treatment experience from a participant perspective is ongoing at the moment.

\section{Acknowledgments}

The author would like to thank the Swedish Prison and Probation Service, especially Cecilia Fielding, Johanna Lätth, Josefine Börjesson, and Martin Lardén, as well as all the participants, therapists and staff involved in the study. Also, thanks to Ann Björkdahl at Ersta Sköndal Bräcke University College, for guidance, especially regarding data analysis and the Emotion-Justice-Interaction research group as well as $\mathrm{PhD}$ supervisors Stefan Sjöström, Maritha Jacobsson, and Rafael Lindqvist at Center for Social Work (CESAR), Department of Sociology at Uppsala University, for valuable input.

\section{Declaration of conflicting interests}

The author declared no potential conflicts of interest with respect to the research, authorship, and/or publication of this article. However, 
author was employed by the Swedish Prison and Probation Service when data for this study was collected.

\section{Funding}

The author(s) received no financial support for the research, authorship, and/or publication of this article.

\section{ORCID iD}

Stina Lindegren (D) https://orcid.org/0000-0002-5875-4521

\section{References}

Allan, M., Grace, R. C., Rutherford, B., \& Hudson, S. M. (2007). Psychometric assessment of dynamic risk factors for child molesters. Sexual Abuse, 19(4), 347-367. https://doi.org/10. 1177/107906320701900402.

Bandura, A (1997). Self-efficacy: The exercise of control. Basingstoke: W. H. Freeman.

Barnett, G. D., Wakeling, H. C., Mandeville-Norden, R., \& Rakestrow, J. (2012). How useful are psychometric scores in predicting recidivism for treated sex offenders?. International Journal of Offender Therapy and Comparative Criminology, 56(3), 420-446. https://doi.org/10.1177/0306624X11403125.

Barnett, G. D., Wakeling, H., Mandeville-Norden, R., \& Rakestrow, J. (2013). Does change in psychometric test scores tell us anything about risk of reconviction in sexual offenders? Psychology, Crime \& Law, 19(1), 85-110. https://doi.org/10.1080/ 1068316X.2011.607820.

Bartholomew, K., \& Horowitz, L. M. (1991). Attachment styles among young adults: A test of a four-category model. Journal of Personality and Social Psychology, 61(2), 226-244. https://doi. org/10.1037/0022-3514.61.2.226.

Beggs, S. M., \& Grace, R. C. (2011). Treatment gain for sexual offenders against children predicts reduced recidivism: A comparative validity study. Journal of Consulting and Clinical Psychology, 79(2), 182-192. https://doi.org/10.1037/a0022900.

Black, D. W. (2000). The epidemiology and phenomenology of compulsive sexual behavior. CNS Spectrums, 5(1), 26-35. https://doi.org/10.1017/S1092852900012645.72

Bonta, J., \& Andrews, D. A. (2017). The psychology of criminal conduct (6th ed.). New York: Routledge.

Bonta, J., Blais, J., \& Wilson, H. A. (2014). A theoretically informed meta-analysis of the risk for general and violent recidivism for mentally disordered offenders. Aggression and Violent Behavior, 19(3), 278-287. https://doi.org/10.1016/j.avb.2014.04.014.

Bowlby, J. (1970). Attachment and loss: Vol. 1. Attachment (2. impr. ed.). London: Hogarth.

Bowlby, J. (1973). Attachment and loss: Vol 2. Separation: Anxiety and anger. London: Hogarth.

Broberg, A., Risholm Mothander, P., Granquist, P., \& Ivarsson, T. (2008). Anknytning i praktiken: Tillämpningar av anknytningsteorin [Attachment in practice: Applications of attachment theory]. Natur \& Kultur.
Bushman, B. J., Baumeister, R. F., \& Phillips, C. M. (2001). Do people aggress to improve their mood? Catharsis beliefs, affect regulation opportunity, and aggressive responding. Journal of Personality and Social Psychology, 81(1), 17-32. https://doi. org/10.1037/0022-3514.81.1.17.

Bőthe, B., Kovács, M., Tóth-Király, I., Reid, R. C., Griffiths, M. D., Orosz, G., \& Demetrovics, Z. (2019). The psychometric properties of the hypersexual behavior inventory using a largescale nonclinical sample. The Journal of Sex Research, 56(2), 180-190. https://doi.org/10.1080/00224499.2018.1494262.

Cohen, J. (1988). Statistical power analysis for the behavioral sciences (2nd ed.). Hillsdale: Lawrence Erlbaum.

Collins, N. L., \& Read, S. J. (1990). Adult attachment, working models, and relationship quality in dating couples. Journal of Personality and Social Psychology, 58(4), 644-663. https://doi. org/10.1037/0022-3514.58.4.644.

Craig, A. R., Franklin, J. A., \& Andrews, G. (1984). A scale to measure locus of control of behaviour. British Journal of Medical Psychology, 57, 173-180.

Craig, L. A., Thornton, D., Beech, A., \& Browne, K. D. (2007). The relationship of statistical and psychological risk markers to sexual reconviction in child molesters. Criminal Justice and Behavior, 34(3), 314-329. https://doi.org/10.1177/0093854806291416.

Crolley, J., Roys, D., Thyer, B. A., \& Bordnick, P. S. (1998). Evaluating outpatient behavior therapy of sex offenders. Behavior Modification, 22(4), 485-501. https://doi.org/10.1177/ 01454455980224003.

D'Orazio, D. M. (2017). Evaluating the responsivity principle in prison-based programs for sexual offending behavior. Journal of Criminal Psychology, 7(3), 192-205. http://dx.doi.org/10.1108/ JCP-12-2016-0045.

DeLisi, M., Caropreso, D. E., Drury, A. J., Elbert, M. J., Evans, J. L., Heinrichs, T., \& Tahja, K. M. (2016). The dark figure of sexual offending: New evidence from federal sex offenders. Journal of Criminal Psychology, 6(1), 3-15. http://dx.doi.org.ezproxy.its. uu.se/10.1108/JCP-12-2015-0030.

Dennis, JA, Khan, O, Ferriter, M, Huband, N, Powney, MJ, \& Duggan, C (2012). Psychological interventions for adults who have sexually offended or are at risk of offending. The Cochrane database of systematic reviews, 12, CD007507. https://doi.org/ 10.1002/14651858.CD007507.pub2.

Drury, A. J., Elbert, M. J., \& DeLisi, M. (2020). The dark figure of sexual offending: A replication and extension. Behavioral Sciences \& the Law, 38(6), 559-570. https://doi.org/10.1002/bsl.2488.

Eisenberg, M. J., van Horn, J. E., Dekker, J. M., Assink, M., van der Put, C. E., Hendriks, J., \& Stams, G. J. J. M. (2019). Static and dynamic predictors of general and violent criminal offense recidivism in the forensic outpatient population: A meta-analysis. Criminal Justice and Behavior, 46(5), 732-750. https://doi. org/10.1177/0093854819826109.

Fisher, D., Beech, A., \& Browne, K. (1998). Locus of control and its relationship to treatment change and abuse history in child sexual abusers. Legal and Criminological Psychology, 3(1), 1-12. https://doi.org/10.1111/j.2044-8333.1998.tb00348.x. 
Fonagy, P., Steele, M., Steele, H., Leigh, T., Kennedy, R., Mattoon, G., \& Target, M. (1995). Attachment, the reflective self, and borderline states: The predictive specificity of the Adult Attachment Interview and pathological emotional development. In Goldberg S., Muir R., \& Kerr J. (Eds), Attachment theory: Social, developmental, and clinical perspectives (pp. 233-279). Routledge.

Gannon, T. A., Olver, M. E., Mallion, J. S., \& James, M. (2019). Does specialized psychological treatment for offending reduce recidivism? A meta-analysis examining staff and program variables as predictors of treatment effectiveness. Clinical Psychology Review, 73, 101752. https://doi.org/10.1016/j.cpr. 2019.101752.

Gillespie, S. M., Bailey, A., Squire, T., Carey, M. L., Eldridge, H. J., \& Beech, A. R. (2018). An evaluation of a community-based psycho-educational program for users of child sexual exploitation material. Sexual Abuse, 30(2), 169-191. https://doi.org/ 10.1177/1079063216639591.

Grady, M. D., Swett, L., \& Shields, J. J. (2016). The impact of a sex offender treatment programme on the attachment styles of incarcerated male sexual offenders. Journal of Sexual Aggression, 22(1), 123-136. https://doi.org/10.1080/13552600.2014.894148.

Griffin, D. W., \& Bartholomew, K. (1994). Models of the self and other: Fundamental dimensions underlying measures of adult attachment. Journal of Personality and Social Psychology, 67(3), 430-445. https://doi.org/10.1037/0022-3514.67.3.430.

Grubbs, J. B., Hoagland, K. C., Lee, B. N., Grant, J. T., Davison, P., Reid, R. C., \& Kraus, S. W. (2020). Sexual addiction 25 years on: A systematic and methodological review of empirical literature and an agenda for future research. Clinical Psychology Review, 82, 101925. https://doi.org/10.1016/j.cpr.2020.101925.

Grønnerød, C., Grønnerød, J. S., \& Grøndahl, P. (2015). Psychological treatment of sexual offenders against children: A meta-analytic review of treatment outcome studies. Trauma, Violence \& Abuse, 16(3), 280-290. https://doi.org/10.1177/1524838014526043.

Gutierrez, L., Wilson, H. A., Rugge, T., \& Bonta, J. (2013). The prediction of recidivism with aboriginal offenders: A theoretically informed meta-analysis. Canadian Journal of Criminology and Criminal Justice, 55(1), 55-99. https://doi.org/10.3138/ cjccj.2011.E.51.

Hallberg, J., Kaldo, V., Arver, S., Dhejne, C., Jokinen, J., \& Öberg, K. G. (2019). A randomized controlled study of groupadministered cognitive behavioral therapy for hypersexual disorder in men. The Journal of Sexual Medicine, 16(5), 733-745. https://doi.org/10.1016/j.jsxm.2019.03.005.

Hanson, R. K. (2014). Treating sexual offenders: How did we get here and where are we headed? Journal of Sexual Aggression, 20(1), 3-8. https://doi.org/10.1080/13552600.2013.861524.

Hanson, R. K., \& Morton-Bourgon, K. E. (2005). The characteristics of persistent sexual offenders: A meta-analysis of recidivism studies. Journal of Consulting and Clinical Psychology, 73(6), 1154-1163. https://doi.org/10.1037/0022-006X.73.6.1154.

Hanson, R. K., Bourgon, G., Helmus, L., \& Hodgson, S. (2009). The principles of effective correctional treatment also apply to sexual offenders. Criminal Justice and Behavior, 36(9), 865-891. https://doi.org/10.1177/0093854809338545.

Harkins, L., \& Beech, A. (2007). Measurement of the effectiveness of sex offender treatment. Aggression and Violent Behavior, 12(1), 36-44. https://doi.org/10.1016/j.avb.2006.03.002.

Hayes, S. C., Strosahl, K., \& Wilson, K. G. (1999). Acceptance and commitment therapy: An experiential approach to behavior change. Guilford Press.

Hook, J. N., Reid, R. C., Penberthy, J. K., Davis, D. E., \& Jennings, D. J. (2014). Methodological review of treatments for nonparaphilic hypersexual behavior. Journal of Sex \& Marital Therapy, 40(4), 294-308. https://doi.org/10.1080/0092623X. 2012.751075.

Jung, S., \& Gulayets, M. (2011). Using clinical variables to evaluate treatment effectiveness in programmes for sexual offenders. Journal of Sexual Aggression, 17(2), 166-180. https://doi.org/ $10.1080 / 13552601003802238$.

Kafka, M. P. (2014). What happened to hypersexual disorder? Archives of Sexual Behavior, 43(7), 1259-1261. https://doi.org/10. 1007/s10508-014-0326-y.

Kim, B., Benekos, P. J., \& Merlo, A. V. (2016). Sex offender recidivism revisited. Trauma, Violence \& Abuse, 17(1), 105-117. https://doi.org/10.1177/1524838014566719.

Kingston, D. A. (2016). Hypersexuality disorders and sexual offending. In Phenix A., \& Hoberman H. M. (Eds), Sexual offending: Predisposing antecedents, assessments and management (pp. 103-118). Springer Science + Business Media. https://doi.org/10.1007/978-1-4939-2416-5_7.

Kingston, D. A., \& Bradford, J. M. (2013). Hypersexuality and recidivism among sexual offenders. Sexual Addiction \& Compulsivity, 20(1-2), 91-105. https://doi.org/10.1080/10720162.2013. 7681.

Kingston, D. A., \& Firestone, P. (2008). Problematic hypersexuality: A review of conceptualization and diagnosis. Sexual Addiction \& Compulsivity, 15(4), 284-310. https://doi.org/10.1080/ 10720160802289249.

Kjellgren, C. (2019). Outcomes for treatment of hypersexual behavior provided by specialized social welfare units. Research on Social Work Practice, 29(1), 103-112. https://doi.org/10.1177/ 1049731518757030.

Klohnen, E. C., Weller, J. A., Luo, S., \& Choe, M. (2005). Organization and predictive power of general and relationshipspecific attachment models: One for all, and all for one? Personality and Social Psychology Bulletin, 31(12), 1665-1682. https://doi.org/10.1177/0146167205278307.

Kriminalvården [Swedish Prison, \& Probation Service] (2019). Sexualbrottsprogram med individuellt fokus (SEIF). Teori- och behandlingsmanual [Sex Offender Program with an Individual Focus (SEIF). Theory and treatment manual].

Kurdek, L. A. (2002). On being insecure about the assessment of attachment styles. Journal of Social and Personal Relationships, 19(6), 811-834. https://doi.org/10.1177/0265407502196005.

Landgren, V., Malki, K., Bottai, M., Arver, S., \& Rahm, C. (2020). Effect of gonadotropin-releasing hormone antagonist on risk of 
committing child sexual abuse in men with pedophilic disorder. JAMA Psychiatry, 77(9), 897-905. https://doi.org/10.1001/ jamapsychiatry.2020.0440.

Levenson, J., \& Prescott, D. S. (2014). Déjà vu: from Furby to Långström and the evaluation of sex offender treatment effectiveness. Journal of Sexual Aggression, 20(3), 257-266. https://doi.org/10.1080/13552600.2013.867078.

Levy, K. N., Meehan, K. B., Kelly, K. M., Reynoso, J. S., Weber, M., Clarkin, J. F., \& Kernberg, O. F. (2006). Change in attachment patterns and reflective function in a randomized control trial of transference-focused psychotherapy for borderline personality disorder. Journal of Consulting and Clinical Psychology, 74(6), 1027-1040. https://doi.org/10. 1037/0022-006X.74.6.1027.

Lewis, A., Grubin, D., Ross, C. C., \& Das, M. (2017). Gonadotrophinreleasing hormone agonist treatment for sexual offenders: A systematic review. Journal of Psychopharmacology, 31(10), 1281-1293. https://doi.org/10.1177/0269881117714048.

Lyn, T. S., \& Burton, D. L. (2004). Adult attachment and sexual offender status. American Journal of Orthopsychiatry, 74(2), 150-159. https://doi.org/10.1037/0002-9432.74.2.150.

Långström, N., \& Hanson, R. K. (2006). High rates of sexual behavior in the general population: Correlates and predictors. Archives of Sexual Behavior, 35(1), 37-52. https://doi.org/10. 1007/s10508-006-8993-y.

Långström, N., Enebrink, P., Laurén, E-.M., Lindblom, J., Werkö, S., \& Hanson, R. K. (2013). Preventing sexual abusers of children from reoffending: Systematic review of medical and psychological interventions. BMJ (Clinical research ed.), 347(7924), f4630. https://doi.org/10.1136/bmj.f4630.

Lösel, F., \& Schmucker, M. (2005). The effectiveness of treatment for sexual offenders: A comprehensive meta-analysis. Journal of Experimental Criminology, 1, 117-146). http://dx.doi.org/10. 1007/s11292-004-6466-7.1

Lösel, F., Link, E., Schmucker, M., Bender, D., Breuer, M., Carl, L., Endres, J., \& Lauchs, L. (2020). On the effectiveness of sexual offender treatment in prisons: A comparison of two different evaluation designs in routine practice. Sexual Abuse, 32(4), 452-475. https://doi.org/10.1177/1079063219871576.

Malandain, L., Blanc, J.-V., Ferreri, F., \& Thibaut, F. (2020). Pharmacotherapy of sexual addiction. Current Psychiatry Reports, 22(6), 30. https://doi.org/10.1007/s11920-020-01153-4.

Mandeville-Norden, R., Beech, A., \& Hayes, E. (2008). Examining the effectiveness of a UK community-based sexual offender treatment programme for child abusers. Psychology, Crime \& Law, 14(6), 493-512. https://doi.org/10.1080/10683160801948907.

Mann, R. E., Hanson, R. K., \& Thornton, D. (2010). Assessing risk for sexual recidivism: some proposals on the nature of psychologically meaningful risk factors. Sexual Abuse, 22(2), 191-217. https://doi.org/10.1177/1079063210366039.

Marsa, F., O’Reilly, G., Carr, A., Murphy, P., O’Sullivan, M., Cotter, A., \& Hevey, D. (2004). Attachment styles and psychological profiles of child sex offenders in Ireland. Journal of Interpersonal Violence, 19(2), 228-251. https://doi.org/10.1177/ 0886260503260328 .
Marshall, W. L. (2005). Therapist style in sexual offender treatment: Influence on indices of change. Sexual Abuse, 17(2), 109-116. https://doi.org/10.1177/107906320501700202.

Marshall, W. L. (2010). The role of attachments, intimacy, and loneliness in the etiology and maintenance of sexual offending. Sexual and Relationship Therapy, 25(1), 73-85. https://doi.org/ 10.1080/14681990903550191.

Marshall, L. E., \& Briken, P. (2010). Assessment, diagnosis, and management of hypersexual disorders. Current Opinion in Psychiatry, 23(6), 570-573. https://doi.org/10.1097/YCO. 0b013e32833d15d1.

Marshall, W. L., \& Marshall, L. E. (2007). The utility of the random controlled trial for evaluating sexual offender treatment: The gold standard or an inappropriate strategy? Sexual Abuse, 19(2), 175-191. https://doi.org/10.1177/107906320701900207.

Marshall, L. E., \& Marshall, W. L. (2009). The Therapist Rating Scale-2. Unpublished manuscript. https://www.researchgate.net/ publication/306889084_The_Therapist_Ratings_Scale-2_TRS2_An_end-of-treatment_outcome_scale_for_determining_sex offender_functioning_on_dynamic_risk_and_engagement_ factors? channel $=$ doi\&linkId $=57 \mathrm{bfb} 9 \mathrm{~d} 908 \mathrm{aeda} 1 \mathrm{ec} 386 \mathrm{c} 838 \&$ showFulltext=true.

Marshall, W. L., \& Marshall, L. E. (2010). Attachment and intimacy in sexual offenders: An update. Sexual and Relationship Therapy, 25(1), 86-90. https://doi.org/10.1080/14681991003589568.

Marshall, W. L., \& Marshall, L. E. (2016). An attachment-based theory of the aetiology of affiliative child molestation. In Boer D. P. (Ed.), The Wiley handbook on the theories, assessment and treatment of sexual offending (pp. 3-24). John Wiley \& Sons. https://doi.org/10.1002/9781118574003.wattso001.

Marshall, L. E., \& O’brien, M. D. (2012). Assessment of sexual addiction. In Beech A. R., Craig L. A., \& Browne K. D. (Eds.), Assessment and treatment of sex offenders (pp. 163-177). John Wiley \& Sons. https://doi.org/10.1002/9780470714362.ch10.

Marshall, W. L., \& O’Brien, M. D. (2013). Balancing clients' strengths and deficits in sexual offender treatmentthe rockwood treatment approach. In Tafrate R. C., \& Mitchell D. (Eds), Forensic CBT (pp. 279-301). John Wiley \& Sons. https://doi. org/10.1002/9781118589878.ch14.

Marshall, W. L., Hall, K. S. K., \& Woo, C.-P. (2016). Sexual functioning in the treatment of sex offenders. In Boer D. P. (Ed.), The Wiley handbook on the theories, assessment and treatment of sexual offending (pp. 1369-1384). John Wiley \& Sons. https:// doi.org/10.1002/9781118574003.wattso065.

Marshall, W. L., Marshall, L. E., \& Olver, M. E. (2017). An evaluation of strength-based approaches to the treatment of sex offenders: A review. Journal of Criminal Psychology, 7(3), 221-228. https://doi.org/10.1108/JCP-04-2017-0021.

Martin, G. M., \& Tardif, M. (2014). What we do and don't know about sex offenders' intimacy dispositions. Aggression and Violent Behavior, 19(4), 372-382. https://doi.org/10.1016/j.avb. 2014.06.002.

Martin, G. M., \& Tardif, M. (2015). Examining sex offenders' intimacy deficits: Their nature and their influence on sexually 
abusive behaviours. Journal of Sexual Aggression, 21(2), 158-178. https://doi.org/10.1080/13552600.2013.849768.

McAnena, C., Craissati, J., \& Southgate, K. (2016). Exploring the role of locus of control in sex offender treatment. Journal of Sexual Aggression, 22(1), 95-106. https://doi.org/10.1080/ 13552600.2015 .1023374$.

Mews, A., Di Bella, L., \& Purver, M. (2017). Impact evaluation of the prison-based core sex offender treatment program. Ministry of Justice Analytical Series. https://www.gov.uk/government/ uploads/system/uploads/attachment_data/file/623876/sotp-reportweb-.pdf.

Miles, L. A., Cooper, R. L., Nugent, W. R., \& Ellis, R. A. (2016). Sexual addiction: A literature review of treatment interventions. Journal of Human Behavior in the Social Environment, 26(1), 89-99. https://doi.org/10.1080/10911359.2015.1062672.

Montogomery-Graham, S. (2016). Conceptualization and assessment of hypersexual disorder: A systematic review of the literature. Sexual Medicine Reviews, 5(2), 146-162. https://doi.org/10. 1016/j.sxmr.2016.11.001.

Mpofu, E., Athanasou, J. A., Rafe, C., \& Belshaw, S. H. (2018). Cognitive-behavioral therapy efficacy for reducing recidivism rates of moderate- and high-risk sexual offenders: A scoping systematic literature review. International Journal of Offender Therapy and Comparative Criminology, 62(1), 170-186. https:// doi.org/10.1177/0306624X16644501.

Ogilvie, C. A., Newman, E., Todd, L., \& Peck, D. (2014). Attachment \& violent offending: A meta-analysis. Aggression and Violent Behavior, 19(4), 322-339. https://doi.org/10.1016/j.avb.2014.04.007.

Olver, M. E., Kingston, D. A., Nicholaichuk, T. P., \& Wong, S. C. P. (2014). A psychometric examination of treatment change in a multisite sample of treated Canadian federal sexual offenders. Law and Human Behavior, 38(6), 544-559. https://doi.org/10. 1037/lhb0000086.

Olver, M. E., Nicholaichuk, T. P., \& Wong, S. C. P. (2014). The predictive and convergent validity of a psychometric battery used to assess sexual offenders in a treatment programme: An 18-year follow-up. Journal of Sexual Aggression, 20(2), 216-239. https://doi.org/10.1080/13552600.2013.816791.

Olver, M. E., Stockdale, K. C., \& Wormith, J. S. (2014). Thirty years of research on the level of service scales: A meta-analytic examination of predictive accuracy and sources of variability. Psychological Assessment, 26(1), 156-176. https://doi.org/10. 1037/a0035080.

Pallant, J. (2016). SPSS survival manual: A step by step guide to data analysis using IBM SPSS (6th ed.). Maidenhead: Open University Press.

Parish, M., \& Eagle, M. N. (2003). Attachment to the therapist. Psychoanalytic Psychology, 20(2), 271-286. https://doi.org/10. 1037/0736-9735.20.2.271.

Pham, A. T., Nunes, K. L., Maimone, S., \& Hermann, C. A. (2021). How accurately can researchers measure criminal history, sexual deviance, and risk of sexual recidivism from self-report information alone? Journal of Sexual Aggression, 27(1), 106-119. https://doi.org/10.1080/13552600.2020.1741709.
Reid, R. C., Garos, S., \& Carpenter, B. N. (2011). Reliability, validity, and psychometric development of the hypersexual behavior inventory in an outpatient sample of men. Sexual Addiction \& Compulsivity, 18(1), 30-51. https://doi.org/10.1080/10720162. 2011.555709.

Reid, R. C., Carpenter, B. N., Hook, J. N., Garos, S., Manning, J. C., Gilliland, R., Cooper, E. B., McKittrick, H., Davtian, M., \& Fong, T. (2012). Report of findings in a DSM-5 field trial for hypersexual disorder. The Journal of Sexual Medicine, 9(11), 2868-2877. https://doi.org/10.1111/j.1743-6109.2012.02936. $\mathrm{x}$.

Ross, E. C., Polaschek, D. L. L., \& Ward, T. (2008). The therapeutic alliance: A theoretical revision for offender rehabilitation. $A g$ gression and Violent Behavior, 13(6), 462-480. https://doi.org/ 10.1016/j.avb.2008.07.003.

Rotter, J. B. (1966). Generalized expectancies for internal versus external control of reinforcement. Psychological Monographs: General and Applied, 80(1), 1-28.

Savard, J., Öberg, K. G., Chatzittofis, A., Dhejne, C., Arver, S., \& Jokinen, J. (2020). Naltrexone in compulsive sexual behavior disorder: A feasibility study of twenty men. The Journal of Sexual Medicine, 17(8), 1544-1552. https://doi.org/10.1016/j. jsxm.2020.04.318.

Schmucker, M, \& Lösel, F (2008). Does sexual offender treatment work? A systematic review of outcome evaluations. Psicothema, 20(1), 10-19.

Schmucker, M., \& Lösel, F. (2015). The effects of sexual offender treatment on recidivism: An international meta-analysis of sound quality evaluations. Journal of Experimental Criminology, 11(4), 597-630. https://doi.org/10.1007/s11292-0159241-z.

Schmucker, M., \& Lösel, F. (2017). Sexual offender treatment for reducing recidivism among convicted sex offenders: A systematic review and meta-analysis. Campbell Systematic Reviews, 13(1), 1-75. https://doi.org/10.4073/csr.2017.8.

Scurich, N., \& John, R. S. (2019). The dark figure of sexual recidivism. Behavioral Sciences \& the Law, 37(2), 158-175. https://doi.org/10.1002/bsl.2400.

Seto, M. C., Marques, J. K., Harris, G. T., Chaffin, M., Lalumière, M. L., Miner, M. H., Berliner, L., Rice, M. E., Lieb, R., \& Quinsey, V. L. (2008). Good science and progress in sex offender treatment are intertwined: A response to Marshall and Marshall (2007). Sexual Abuse, 20(3), 247-255. https://doi.org/ 10.1177/1079063208317733.

Simpson, J. A., Rholes, W. S., \& Nelligan, J. S. (1992). Support seeking and support giving within couples in an anxietyprovoking situation: The role of attachment styles. Journal of Personality and Social Psychology, 62(3), 434-446. https://doi. org/10.1037/0022-3514.62.3.434.

Smallbone, S. W., \& Dadds, M. R. (2000). Attachment and coercive sexual behavior. Sexual Abuse, 12(1), 3-15. https://doi.org/10. 1177/107906320001200102.

Smallbone, S. W., \& McCabe, B.-A. (2003). Childhood attachment, childhood sexual abuse, and onset of masturbation among adult 
sexual offenders. Sexual Abuse, 15(1), 1-9. https://doi.org/10. 1177/107906320301500101.

Soldino, V., \& Carbonell-Vayá, E. J. (2017). Effect of treatment on sex offenders' recidivism: A meta-analysis. Anales de Psicología, 33(3), 578. https://doi.org/10.6018/analesps.33.3. 267961.

Stewart, H., \& Fedoroff, J. P. (2014). Assessment and treatment of sexual people with complaints of hypersexuality. Current Sexual Health Reports, 6(2), 136-144. https://doi.org/10.1007/s11930014-0017-7.

Stirpe, T., Abracen, J., Stermac, L., \& Wilson, R. (2006). Sexual offenders' state-of-mind regarding childhood attachment: A controlled investigation. Sexual Abuse, 18(3), 289-302. https:// doi.org/10.1007/s11194-006-9022-3.

Sturmey, P., \& McMurran, M. (Eds.). (2011). Forensic case formulation. John Wiley \& Sons. https://doi.org/10.1002/ 9781119977018.

Sundell, K., \& Åhsberg, E. (2018). Trends in methodological quality in controlled trials of psychological and social interventions. Research on Social Work Practice, 28(5), 568-576. https://doi. org/10.1177/1049731516633297.

Swedish Research Council (2017). Good research practice. https:// www.vr.se/download/18.5639980c162791bbfe697882/ 1555334908942/Good-Research-Practice_VR_2017.pdf.

Thornton, D. (2002). Constructing and testing a framework for dynamic risk assessment. Sexual Abuse, 14(2), 139-153. https:// doi.org/10.1177/107906320201400205.

Walfish, S., McAlister, B., O’Donnell, P., \& Lambert, M. J. (2012). An investigation of self-assessment bias in mental health providers. Psychological Reports, 110(2), 639-644. https://doi.org/ 10.2466/02.07.17.PR0.110.2.639-644.

Walters, G. D., Knight, R. A., \& Långström, N. (2011). Is hypersexuality dimensional? Evidence for the DSM-5 from general population and clinical samples. Archives of Sexual Behavior, 40(6), 1309-1321. https://doi.org/10.1007/s10508-010-9719-8.

Ward, T., Hudson, S. M., \& Marshall, W. L. (1996). Attachment style in sex offenders: A preliminary study. Journal of Sex Research, 33(1), 17-26. https://doi.org/10.1080/00224499609551811.

Westfelt, L. (2008). Brottsoffers benägenhet att polisanmäla brott [The propensity of victims to report crime to the police]. Brottsförebyggande rådet the Swedish National Council for Crime Prevention.

Wielinga, F., Margeotes, K., \& Olver, M. E. (2021). Clinical and risk relevance of intimacy and loneliness in a treated sample of men who have offended sexually. Journal of Sexual Aggression, 27(1), 35-51. https://doi.org/10.1080/13552600.2019.1698778.

Wilson, M., \& Fischer, B. (2018). Drawing out the shame: A comparative study on the effectiveness of art therapy with hypersexual adults. The Arts in Psychotherapy, 60, 19-25. https://doi.org/10.1016/j.aip.2018.03.002.

Winder, B., Lievesley, R., Elliott, H., Hocken, K., Faulkner, J., Norman, C., \& Kaul, A. (2018). Evaluation of the use of pharmacological treatment with prisoners experiencing high levels of hypersexual disorder. The Journal of Forensic Psychiatry \& Psychology, 29(1), 53-71. https://doi.org/10.1080/14789949.2017.1337801.

Wooditch, A., Tang, L. L., \& Taxman, F. S. (2014). Which criminogenic need changes are most important in promoting desistance from crime and substance use?. Criminal Justice and Behavior, 41(3), 276-299. https://doi.org/10.1177/0093854813503543.

World Health Organization (2021). ICD-11 for mortality and morbidity statistics (version: 5/2021). https://icd.who.int/ browse11/1-m/en\#/http $\% 3 a \% 2 f \% 2$ fid.who.int $\% 2$ ficd $\% 2$ fentity $\% 2 \mathrm{f} 1630268048$.

Zapf, J. L., Greiner, J., \& Carroll, J. (2008). Attachment styles and male sex addiction. Sexual Addiction \& Compulsivity, 15(2), 158-175. https://doi.org/10.1080/10720160802035832. 